\title{
Sialendoscopic treatment of recurrent juvenile parotitis: A South African case series
}

\author{
S Honnet, ${ }^{1}$ BSc, MB BCh; O Edkins, ${ }^{1,2}$ MB BCh, FCORL (SA), MMed (Otol) \\ ${ }^{1}$ Department of Otorhinolaryngology, New Somerset Hospital, Cape Town, South Africa \\ ${ }^{2}$ Department of Otorhinolaryngology, Faculty of Health Sciences, University of Cape Town, South Africa
}

Corresponding author: S Honnet (simonhonnet@yahoo.com)

\begin{abstract}
Background. Recurrent juvenile parotitis (RJP) is a well-recognised cause of parotitis in childhood. Sialendoscopy has been extensively used for the investigation and treatment of many benign salivary disorders, and now offers a minimally invasive approach to RJP.

Objectives. To investigate the epidemiology and disease profile of RJP, and review the efficacy of sialendoscopy for its investigation and treatment.

Methods. The relevant literature on RJP was reviewed, and a retrospective folder review was performed for all patients who had undergone sialendoscopy for RJP at two South African (SA) hospitals between April 2013 and September 2015. Patients' epidemiological and clinical data were recorded, as well as the findings and outcomes of ultrasonography and sialendoscopy. In particular, the time following treatment without any further recurrences was recorded as a measure of success.

Results. Five children underwent sialendoscopic investigation and treatment for RJP. Their demographic and disease profiles and the results of investigations and treatments were in keeping with published literature. No surgical complications occurred, and no patients reported any further symptoms postoperatively, with an average follow-up of 22 months.

Conclusion. Although small in sample size, this is the first reported case series in the SA literature on the use of sialendoscopy for RJP, and the results are consistent with internationally published data. Sialendoscopy is regarded as safe and effective for the diagnosis and management of RJP, and should be considered for patients who remain symptomatic after conservative management.
\end{abstract}

S Afr Med J 2016;106(8):899-812. DOI:10.7196/SAMJ.2016.v106i8.10561

Parotitis is a common condition in paediatric populations, and although it is usually a self-limiting viral infection, one should bear the other differential diagnoses in mind. Recurrent juvenile parotitis (RJP) is an inflammatory disorder of the parotid salivary glands in young children, and is second in incidence only to mumps. ${ }^{[1]}$ The disease is defined as a recurrent nonspecific, non-obstructive parotitis. It is usually unilateral, but may also be bilateral, with symptoms worse on one side. Perhaps its most recognisable feature is the temporal pattern of its onset and episodic recurrences. It most commonly begins between the ages of 3 and 6 years, and has a male preponderance. ${ }^{[1]}$ Less commonly, the disease may only begin after puberty; curiously, females are then more affected. ${ }^{[1]}$ RJP may initially be mistaken for mumps, or may even go unrecognised. The healthcare practitioner sometimes only realises after the second or third episode that the diagnosis should be reviewed. Episodes typically last for a few days, and recur at intervals of between 2 weeks and 2 months. ${ }^{[2]}$ The frequency of recurrences typically peaks between the ages of 5 and 7 years. With the onset of puberty, recurrences often become less frequent and less severe, and then usually completely burn out spontaneously. In some unfortunate individuals, however, the disease continues into adulthood, ${ }^{[3]}$ leading to a progressive loss of parenchymal function, reducing secretions by $50-80 \%$ in severe cases. ${ }^{[4]}$

Acute episodes of RJP are characterised by tender parotid or facial swelling, fever and malaise. Patients commonly have erythema of the overlying skin, and debris resembling snowflakes is occasionally present, with white mucopurulent fluid that can be milked from the Stensen's duct papilla opposite the second maxillary molar tooth. ${ }^{[5]}$ Understandably, the frequency of recurrences largely determines the patient's quality of life.

Ultrasonography is useful in confirming the disease and for follow-up, and typically demonstrates multiple hypoechoic areas of
2 - $4 \mathrm{~mm}$ diameter. ${ }^{[6]}$ Punctate calcifications are often present, but are not specific to RJP, occurring following any cause of chronic inflammation. Although ultrasonography has become the imaging modality of choice, it is sometimes not even necessary: if the clinical history and physical examination are typical of RJP, it is entirely reasonable to proceed directly to sialendoscopy, since recent studies ${ }^{[7]}$ have demonstrated sufficient diagnostic accuracy.

Where available, sialography has also been useful in diagnosing RJP in the past, with the very characteristic patterns of multiple areas of punctate and globular sialectasis scattered throughout the glandular parenchyma. However, its application in children is limited owing to the invasive nature of the cannulation, and potentially hazardous exposure to ionising radiation. ${ }^{[8]}$ With the increasing image quality of modern ultrasound machines, ultrasonography has superseded sialography. ${ }^{[5,9]}$

The aetiology and pathogenesis of RJP remain unknown despite several hypotheses and investigations over the years. Genetic causes, with autosomal dominantly inherited abnormalities of the ductal system, ${ }^{[10]}$ immune-mediated causes, with immaturities especially of IgA in the immune system, ${ }^{[11]}$ and infectious causes, with ascending oral infections, ${ }^{[9]}$ have all been hypothesised, but to date none of them has been proven, suggesting that the cause may in fact be multifactorial. Any process that results in a reduced ability of the parotid gland to drain saliva would trigger an inflammatory cycle, with reduced salivary flow, accumulation of debris, and further obstruction and inflammation. ${ }^{[12]}$

Some families have been identified with multiple siblings in multiple generations being affected in what appears to be a pattern of autosomal dominant inheritance, with incomplete penetrance and variable expression. ${ }^{[10]}$

The most important differential diagnoses of painful parotid swellings include: 
- Mumps. A highly contagious paramyxovirus infection, with a prodromal phase of constitutional symptoms followed by bilateral painful parotid swelling, and less commonly orchitis or meningoencephalitis. There is only one serotype, so infection confers lifelong immunity, preventing recurrences.

- Bacterial parotitis (Streptococcus spp. and Staphylococcus spp.). Sudden onset of unilateral painful parotid swelling, with purulent exudate from the papilla.

- Strictures and sialolithiasis. Intermittent unilateral painful parotid swelling while eating; stones are often palpable.

- Pneumoparotitis after playing a wind instrument, glass blowing or SCUBA diving.

In a patient with painless parotid swellings, lymphoepithelial cysts of HIV are probably most important to consider, being highly stigmatised in South African (SA) society. They are usually bilateral, completely nontender swellings, persistent for long periods if the patient is not on antiretroviral treatment $^{[13]}$ and often associated with other stigmata of HIV or AIDS.

Given the uncertainty regarding the aetiology of the disease, there has been no universal consensus on appropriate treatment of RJP and, until recently, no means at all of preventing further recurrences or eventual destruction of glandular parenchyma and function.

In 1964, Katzen and Du Plessis ${ }^{[14]}$ described a large SA case series of 44 patients with RJP, but the treatment modalities in that era were quite different, so renewed interest in the subject is overdue. Sialendoscopic techniques, introduced in the 1990s for other benign salivary diseases, have now become widely used in the investigation and treatment of RJP, and as initial outcomes are promising, they are gaining worldwide approval.

\section{Methods}

The study was a retrospective review of hospital folders of patients who underwent sialendoscopy for RJP between April 2013 and September 2015, performed by a single surgeon (OE, the senior author) at two different hospitals. Ethics approval was granted by the Human Research Ethics Committee, Faculty of Health Sciences, University of Cape Town (Ref. 659/2015).

The aspects reviewed included: $(i)$ patient demographics (age, gender and HIV status); (ii) disease profile (number of previous episodes over what period, and whether unilateral or bilateral); (iii) ultrasonographic characteristics; (iv) sialendoscopic findings and the use of complementary treatment(s); and $(v)$ outcomes of treatment (complications of endoscopy, and the need for further treatment).

\section{Results}

Five children required sialendoscopy for recurrences of RJP that did not respond to conservative treatment modalities. The diagnoses were made clinically, and on the

Table 1. Patient demographics and RJP disease profile

\begin{tabular}{|c|c|c|c|c|c|c|}
\hline \multirow{2}{*}{$\begin{array}{l}\text { Patient } \\
\text { No. }\end{array}$} & \multicolumn{3}{|c|}{ Demographics } & \multicolumn{3}{|c|}{ Disease profile } \\
\hline & Age (years) & Sex & HIV status & Number of previous episodes & Period of symptoms (years) & Unilateral or bilateral \\
\hline 1 & 11 & M & Unexposed & 4 & 1 & Unilateral \\
\hline 2 & 7 & $\mathrm{M}$ & Unexposed & Numerous & 4 & Bilateral \\
\hline 3 & 5 & $\mathrm{M}$ & Unexposed & $4-5$ & 1 & Unilateral \\
\hline 4 & 6 & $\mathrm{~F}$ & Not tested & 4 & 1 & Unilateral \\
\hline 5 & 5 & M & Not tested & 5 & 1 & Unilateral \\
\hline
\end{tabular}

Table 2. Results and outcomes of ultrasonographic and sialendoscopic investigation and treatment of RJP

\begin{tabular}{|c|c|c|c|c|c|c|}
\hline \multirow[b]{2}{*}{$\begin{array}{l}\text { Patient } \\
\text { No. }\end{array}$} & \multirow[b]{2}{*}{ Ultrasonographic findings } & \multirow[b]{2}{*}{ Sialendoscopic findings } & \multirow[b]{2}{*}{ Other treatment } & \multicolumn{3}{|c|}{ Outcome of treatment } \\
\hline & & & & Complications & $\begin{array}{l}\text { Duration of } \\
\text { follow-up } \\
\text { (months) }\end{array}$ & $\begin{array}{l}\text { Further } \\
\text { treatment } \\
\text { needed }\end{array}$ \\
\hline 1 & $\begin{array}{l}\text { R parotid } \\
\text { LN/cyst } 2 \times 3 \mathrm{~mm} \\
\text { Normal ducts }\end{array}$ & Normal & Analgesics, NSAIDs & None & 9 & None \\
\hline 2 & $\begin{array}{l}\text { R parotid enlarged } \\
\text { Bilateral intraparotid LNs: } \\
\text { R } 10 \times 9 \mathrm{~mm} \text {; } \\
\text { L } 7 \times 5 \mathrm{~mm} \\
\text { Multiple cervical LNs }\end{array}$ & $\begin{array}{l}\text { Atrophic ducts } \\
\text { Mild stranding } \\
\text { Minimal slough }\end{array}$ & Analgesics, NSAIDs & None & 10 & None \\
\hline 3 & Multiple hypoechoic lesions & $\begin{array}{l}\text { Patchy ductal atrophy } \\
\text { Tortuous ducts } \\
\text { Slough }\end{array}$ & $\begin{array}{l}\text { Analgesics, NSAIDs } \\
\text { Augmentin for purulent } \\
\text { discharge }\end{array}$ & None & 10 & None \\
\hline 4 & $\begin{array}{l}\text { L parotid enlarged } \\
\text { Reactive intraparotid LNs } \\
\text { Multiple hypoechoic lesions }\end{array}$ & $\begin{array}{l}\text { Atrophic ducts } \\
\text { Slough }\end{array}$ & Analgesics, NSAIDs & None & 9 & None \\
\hline 5 & $\begin{array}{l}\text { R parotid enlarged } \\
\text { Multiple hypoechoic lesions }\end{array}$ & $\begin{array}{l}\text { Atrophic ducts } \\
\text { Slough }\end{array}$ & Analgesics, NSAIDs & None & 29 & None \\
\hline
\end{tabular}


basis of characteristic ultrasonographic appearances when available.

Table 1 shows that the demographic profiles were as expected, with a range of ages from 5 to 11 years and a male preponderance. Most patients had four or five episodes over the course of about a year before presentation and, as expected, most of these were unilateral disease. One patient had bilateral disease, giving a total of six parotid glands investigated in five children. Three patients were known to be HIV 'unexposed', and the other two were not tested, because although both RJP and lymphoepithelial cysts of HIV demonstrate multiple hypoechoic lesions on ultrasonography, the two diseases are clinically distinct. Most importantly, lymphoepithelial cysts of HIV produce a painless and invariably bilateral parotid swelling, without any signs of inflammation.

Table 2 shows that the most common ultrasonographic finding in this case series was multiple hypoechoic lesions in the symptomatic parotid gland and a completely normal, homogeneous echogenic glandular texture on the asymptomatic side (Fig. 1).

All patients underwent sialendoscopy as a day-case procedure under general anaesthesia during asymptomatic intervals in the course of their disease. Only the symptomatic parotid glands were treated in cases of unilateral disease. Stensen's duct was lavaged using either saline or a steroid solution.

Operative findings from sialendoscopy in 4 of the 5 patients included pale, avascular and stenotic ducts, with fibrinous slough, mucus plugs and debris in the lumens, which is consistent with internationally published data. ${ }^{[1,8]}$

All patients received analgesics and nonsteroidal anti-inflammatory drugs. Only one patient required antibiotic treatment, for a secondary bacterial parotitis with purulent discharge from the papilla of Stensen's duct.

Follow-up was booked for 1 month after surgery to confirm normal salivary flow and exclude surgical complications such as iatrogenic stenosis of the papilla. Patients were advised to book further follow-up if any symptoms recurred. All patients had direct telephonic access in the event of further recurrences or complaints.

No surgical complications and no further recurrences requiring treatment were noted in any of the five patients during followup of between 9 and 29 months (mean 22 months).

\section{Discussion}

Treatment of RJP is aimed at relief of acute episodes and prevention of glandular paren-
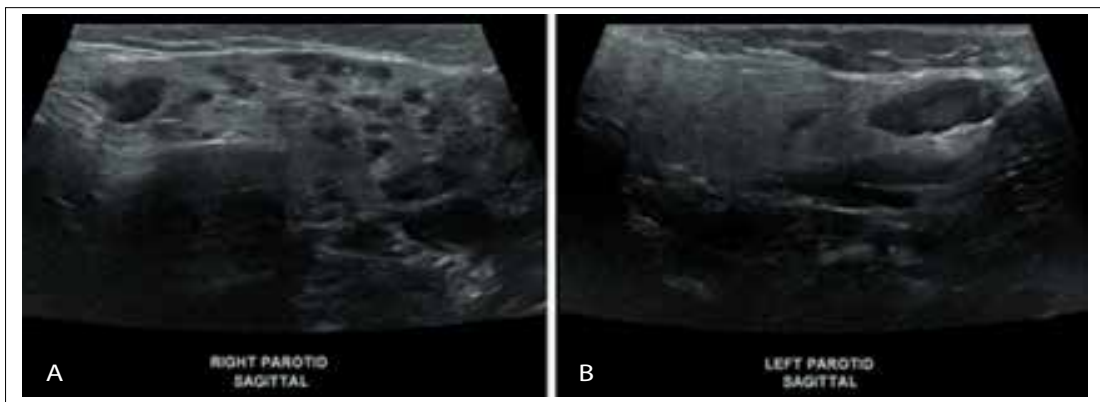

Fig. 1. A: Unilateral right-sided RJP; B: normal left parotid gland.

chymal destruction. Sialogogues, gland massage, attention to good oral hygiene and maintenance of adequate oral hydration are important initial steps. ${ }^{[1]}$ Historically, treatment of RJP consisted mostly of watchful waiting, on the basis that most cases resolve spontaneously by puberty. However, significant morbidity is associated with this approach; some cases do not resolve at all, potentially resulting in loss of parenchymal tissue and function. Antibiotics are controversial: in Katzen and Du Plessis ${ }^{\text {[14] }} 1964$ case series, some patients experienced good relief of symptoms after 3 - 7 days of penicillin, but they also noted that the patients who were not given antibiotics recovered just as well, and both groups of patients still went on to have recurrent attacks. Having said this, some patients may become systemically ill with a secondary bacterial parotitis, which would certainly warrant antibiotic treatment.

With regard to surgical techniques, Stensen's duct ligation, tympanic neurectomy and superficial or total parotidectomy have been described, but with limited success. While the latter is certainly curative, all open surgical procedures are associated with a significant risk of facial nerve injury, especially in the context of recurrent episodes of parotitis, with resultant fibrosis of the gland.

Currently there is a paradigm shift towards gland preservation with minimally invasive modalities such as sialendoscopy. This allows endoscopic visualisation of the salivary ductal system, and permits both accurate diagnosis and treatment, thus providing an alternative to open surgery and its complications. A separate irrigation channel in the scope allows the surgeon to flush out the salivary ductal system with saline and/ or a steroid solution. This not only rinses out debris and inflammatory mediators, but mechanically dilates the ducts for diagnostic visualisation, and the dilatation is also therapeutic. This mechanical lavage and dilatation is thought to be the mechanism by which the underlying inflammatory cycle is interrupted. ${ }^{[1,12]}$ The procedure is usually

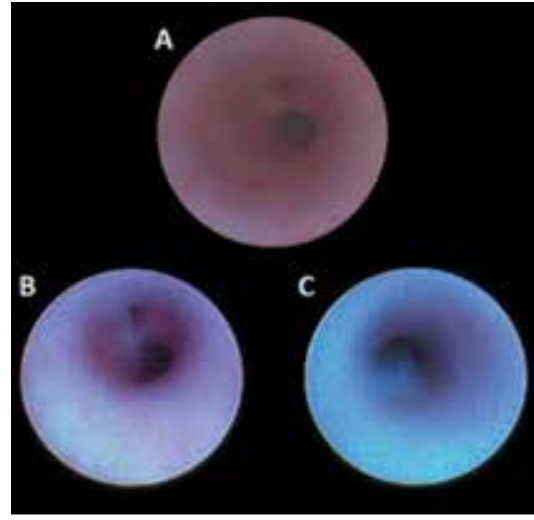

Fig. 2. A: Endoscopically normal Stensen's duct $B$ and $C$ : sialendoscopic features of RJP.

performed as day-case surgery, reducing the hospital stay, and the only contraindication to sialendoscopy is acute sialadenitis, since the inflamed and friable ducts are more prone to injury, increasing the risk of creating a false tract and spreading infection throughout the parenchyma of the gland and soft tissues of the head and neck.

It is noteworthy that in one patient in our series the findings on ultrasonography and sialendoscopy were entirely normal. This is thought to be due to early presentation of RJP. Early recognition and diagnosis may allow treatment to be initiated before the onset of structural changes to the parotid parenchyma, which may confer a better prognosis. Further prospective studies would be needed to demonstrate such benefits.

Shacham et al..$^{[15]}$ showed excellent outcomes in a long-term follow-up of 70 children treated for RJP with sialendoscopy, in over $90 \%$ of whom a single sialendoscopic procedure with lavage of the parotid gland was sufficient to prevent any further recurrences of the disease. While some authors ${ }^{[8]}$ propose anecdotal evidence to support bilateral sialendoscopic treatment in all cases, irrespective of the laterality of symptoms, there is very little evidence to suggest that this is in any way effective in preventing disease in the opposite gland. Our case series demonstrates success with a 
more conservative regimen, operating only on symptomatic glands and achieving results that compare favourably with internationally published outcomes.

\section{Conclusion}

Clinicians should consider the diagnosis of RJP in the differential diagnosis of episodic parotitis, and refer appropriately for further investigations and treatment. The use of antibiotics should be limited to treatment of acute episodes associated with purulent discharge from Stensen's duct, or an acutely unwell child. The role of invasive surgical options is declining with the advent of minimally invasive procedures such as sialendoscopy. This case series concurs with the current literature, and suggests that sialendoscopy performed during asymptomatic intervals is safe and effective for the diagnosis and management of RJP, and should be considered for patients in whom conservative management fails. Being a retrospective case series, this represents grade IV level of evidence.

\section{References}

1. Canzi P, Occhini A, Pagella F, et al. Sialendoscopy in juvenile recurrent parotitis: A review of the literature. Acta Otorhinolaryngol Ital 2013;33(6):367-373.
2. Ericson S, Zetterlund B, Ohman J. Recurrent parotitis and sialectasis in childhood: Clinical, radiologic, immunologic, bacteriologic, and histologic study. Ann Otol Rhinol Laryngol 1991;100(7):527-535, DOI: $10.1177 / 000348949110000702$

3. Porter SR. Non-neoplastic salivary gland diseases. In: Gleeson M, ed. Scott-Brown's Otorhinolaryngology, Head and Neck Surgery. 7th ed. London: Hodder Arnold, 2008:898-1920. 4. Mandel L, Kaynar A. Recurrent parotitis in children. NY State Dent J 1995;61(2):22-25.

4. Mandel L, Kaynar A. Recurrent parotitis in children. NY State Dent J 1995;61(2):22-25.
5. Leerdam CM, Martin HC, Isaacs D. Recurrent parotitis of childhood. J Paediatr Child Health 5. Leerdam CM, Martin HC, Isaacs D. Recurrent parotitis
2005;41(12):631-634. DOI:10.1111/j.1440-1754.2005.00773.x

6. Nozaki $\mathrm{H}$, Harasawa A, Hara $\mathrm{H}$, et al. Ultrasonographic features of recurrent parotitis in childhood. Pediatr Radiol 1994;24(2):98-100. DOI:10.1007/BF02020162

7. Motamed M, Laugharne D, Bradley PJ. Management of chronic parotitis: A review. J Laryngol Otol 2003;117(7):521-526. DOI:10.1258/002221503322112923

8. Nahlieli O, Shacham R, Shlesinger M, et al. Juvenile recurrent parotitis: A new method of diagnosis and treatment. Pediatrics 2004;114(1):9-12. DOI:10.1542/peds.114.1.9

9. Chitre VV, Premchandra DJ. Recurrent parotitis: Regular review. Arch Dis Child 1997;77(4):359-363. DOI:10.1136/adc.77.4.359

10. Reid E, Douglas F, Crow Y, et al. Autosomal dominant juvenile recurrent parotitis. J Med Genet 1998;35(5):417-419. DOI:10.1136/jmg.35.5.417

11. Shkalim V, Monselise Y, Mosseri R, et al. Recurrent parotitis in selective IgA deficiency. Pediatr Allergy Immunol 2004;15(3):281-283. DOI:10.1111/j.1399-3038.2004.00163.x

12. Jabbour N, Tibesar R, Lander T, et al. Sialendoscopy in children. Int J Pediatr Otorhinolaryngol 2010;74(4):347-350. DOI:10.1016/j.ijporl.2009.12.013

13. Meyer E, Lubbe D, Fagan J. Alcohol sclerotherapy of human immunodeficiency virus related lymphoepithelial cysts. J Laryngol Otol 2008;123(4):422-425. DOI:10.1017/S0022215108003149

14. Katzen M, du Plessis D. Recurrent parotitis in children. S Afr Med J 1964;38(1):122-128.

15. Shacham R, Droma EB, London D, et al. Long-term experience with endoscopic diagnosis and treatment of juvenile recurrent parotitis. J Oral Maxillofac Surg 2009;67(1):162-167. DOI:10.1016/j. joms.2008.09.027

Accepted 25 January 2016. 